\title{
A Morphological and Morphometric Study of Proximal and Distal Ends of Dry Radii with its Clinical Implications
}

\author{
Chandni Gupta, Sneha Guruprasad Kalthur, J. C. Malsawmzuali, Antony Sylvan D’souza
}

Background: Knowledge of the size and shape of radial head is essential for construction of radial head prosthesis. Further, the measurements of bicipital tuberosity and its angular relationship to radial head are significant in surgical techniques, like in the reconstruction of biceps tendon. Even the morphometry of the distal radius is significant in numerous clinical orthopedic situations such as reduction of distal radius fractures and in the design of distal radius prosthesis. So, the aim of the study was to determine the morphometric parameters of proximal and distal radius in dry adult Indian radius.

Methods: $\quad$ Fifty intact adult Indian radius (right $=23$, left $=27$ ) were chosen, and the various parameters of proximal and distal ends of radius were studied. Student's $t$-test was done to correlate all these parameters on the right and left sides.

Results: The mean length of radius, height of head at medial and lateral ends, head anteroposterior and transverse diameter, head thickness at ventral, dorsal, and lateral ends were $23.5,0.90,0.75,1.91,1.85,0.42,0.32$, and $0.30 \mathrm{~cm}$, respectively. The mean depth of articular facet, length of neck, proximal and distal neck diameter, width and length of bicipital tuberosity, and radial circumference at bicipital tuberosity were $0.19,1.19,1.36,1.31,1.23,1.97$, and

\begin{abstract}
At a Glance Commentary
Scientific background of the subject

Nowadays fractures of radial head and neck are more common. Surgical management of displaced and comminuted radial head fractures needs replacement with radial head prosthesis if reconstruction is not possible.
\end{abstract}

\section{What this study adds to the field}

The results of our study are important in making anatomically and biomechanically correct radial head as well as the distal end of radius prosthes is. In our study, we looked for the prevalence of types of curvature at the head and neck zone, which is important for the surgeon to select the most appropriate plate and to achieve good anatomical restoration of the proximal radius. The dimensions of the bicipital tuberosity will facilitate in various surgical procedures such as reconstruction of the distal biceps tendon. $4.54 \mathrm{~cm}$, respectively. The mean length of styloid process, oblique and transverse width of lower end, anteroposterior diameter of lower end, and angle of radial inclination were $0.98 \mathrm{~cm}, 2.81 \mathrm{~cm}, 2.59 \mathrm{~cm}, 1.86 \mathrm{~cm}$, and $25.05^{\circ}$, respectively.

Conclusion: This study will be useful for orthopedic surgeons in making prosthesis for the proximal and distal ends of radius.

(Biomed J 2015;38:323-328)

Key words: angle of inclination, head, neck, prosthesis, radius

$\mathrm{R}$ adial head and neck fractures constitute $1.7-5.4 \%$ of all fractures. Radial head fractures alone constitute one-third of all elbow fractures and about $20 \%$ of all elbow trauma cases.$^{[1]}$ An appreciation of the part played by radial head in the overall stability of elbow and forearm has en- couraged several investigators to recommend conservation of radial head, either by operative fixation or by prosthetic replacement.

Distal radius fractures comprise $8-15 \%$ of all upper limb fractures. So, information of normal values of distal

From the Department of Anatomy, Kasturba Medical College, Manipal, India

Received: Aug. 23, 2014; Accepted: Jan. 20, 2015

Correspondence to: Dr. Chandni Gupta, Department of Anatomy, Kasturba Medical College, Manipal, India. State Highway 65, Madhav Nagar, Manipal 576104, India. Tel: 91-820-2922327; Fax: 91-820-2571927; Email: chandnipalimar@ gmail.com

DOI: $10.4103 / 2319-4170.151033$ 
morphometry is significant, as one of the goals of management for fractures is to reestablish anatomical configuration. ${ }^{[2]}$ The quality of reduction is evaluated chiefly by the degree of restoration of radial angle of inclination and palmar tilt. ${ }^{[3]}$ Radial shortening, increased radial inclination, and dorsal angulation cause substantial modifications in the kinematics of the wrist joint and grip strength. Even pronation and supination are associated with the initial length of radius and dorsal angulation. ${ }^{[4-6]}$

So, the aim of the study was to determine the morphometric parameters and the morphology of head, neck, bicipital tuberosity, and the distal end of dry radius in South Indian population.

\section{METHODS}

Fifty intact adult radius (right $=23$, left $=27$ ) were chosen, and the bones with incomplete ossification, previous fracture, or deformity were excluded from the study. Various parameters of proximal and distal end of radius were measured in supinated as well as semi-pronated position of radius [Figures 1-5]:

- Length of radius (L)- The radial length was measured as the distance between the tip of radial styloid and the most lateral portion of the radial head

- Height of radial head in medial (MH) and lateral (LH) sides- The medial and lateral height of the radial head was measured as the distance between the radial lip and the head-neck border

- Anteroposterior diameter (APD and transverse diameters (TD) of the radial head

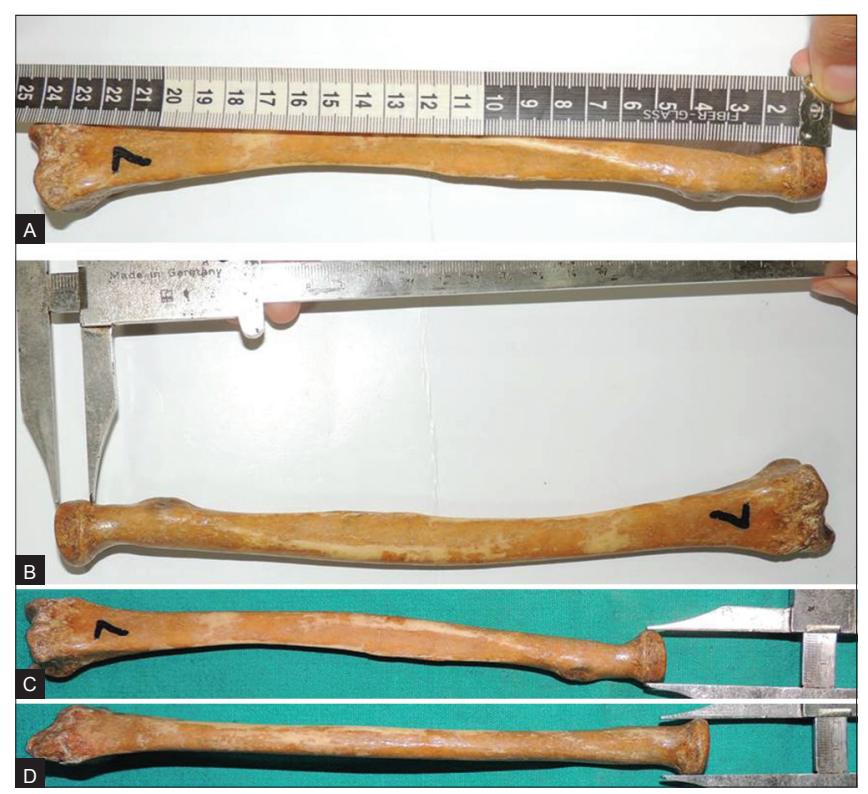

Figure 1: Various measurements done on radius: (A) length of radius, (B) height of radial head at its medial end, (C) transverse diameter of head, (D) AP diameter of head.
- Thickness of ventral (TVC), lateral (TLC), and dorsal (TDC) curves

- Depth of articular facet (D)

- Prevalence of types of shapes of the radial head

- Length of neck of radius (NL)- The neck length was measured as the distance between the head-neck border and the superior border of bicipital tuberosity

- Proximal radial neck diameter (PND) and distal radial neck diameter (DND)- Proximal and distal radial neck diameter was measured lateromedially

- Prevalence of types of curvature at the head and neck zone- Types of curvature were classified as flat profile and low concave curvature

- Width of bicipital tuberosity (WBT)

- Length of bicipital tuberosity (LBT)

- Circumference of radius at bicipital tuberosity (CRBT)- Circumference at radial tuberosity was taken at the maximum convexity of radial tuberosity and this was measured with the help of a measuring tape

- Prevalence of morphological variants of bicipital tuberosity- Morphological variants of bicipital tuberosity were classified as smooth, a single ridge, or bifid ridge

- Angle of radial inclination- The angle of radial inclination was measured as the angle between a line joining the tip of radial styloid and the medial edge of the distal end of radius and a line perpendicular to the long axis of the radius

- Length of radial styloid (SL) process- Length of radial styloid was measured as the distance between the tip of radial styloid and a perpendicular to the long axis of the radius at the level of the medial edge of distal radius

- Widths of distal radius oblique (WDO) and transverse (WDT)- WDT was measured as the maximum width of the distal radius along a perpendicular to the

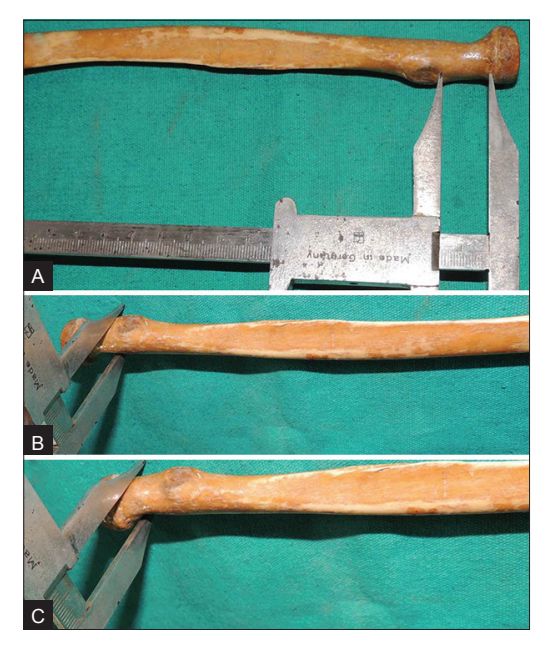

Figure 2: Various measurements done on radius: (A) length of radius neck, (B) distal neck diameter, (C) proximal diameter of neck. 
long axis of the radius, at the level of the medial edge of radius. WDO was measured as the oblique width of the radius along its distal margin

- Anteroposterior diameter (APD de) of distal end.

All these measurements were taken with the help of vernier caliper. Angle of inclination was measured with the help of a protractor. Student's $t$-test was used to correlate all these parameters on the right and left sides. Data were analyzed using IBM SPSS Statistics for Windows version 20.0, USA.

\section{RESULTS}

The mean and range of all parameters of the right and left radii are shown in Tables 1 and 2.

The mean length of radius, height of the radial head at medial and lateral ends, head AP, transverse diameter, head thickness at the ventral, dorsal, and lateral sides, and depth of articular facet in total radius were 23.5, 0.9, 0.75, 1.91, $1.85,0.42,0.32,0.30$, and $0.19 \mathrm{~cm}$, respectively.

The mean neck length, proximal and distal neck diameter, width and length of bicipital tuberosity, radial circumference at bicipital groove, length of styloid

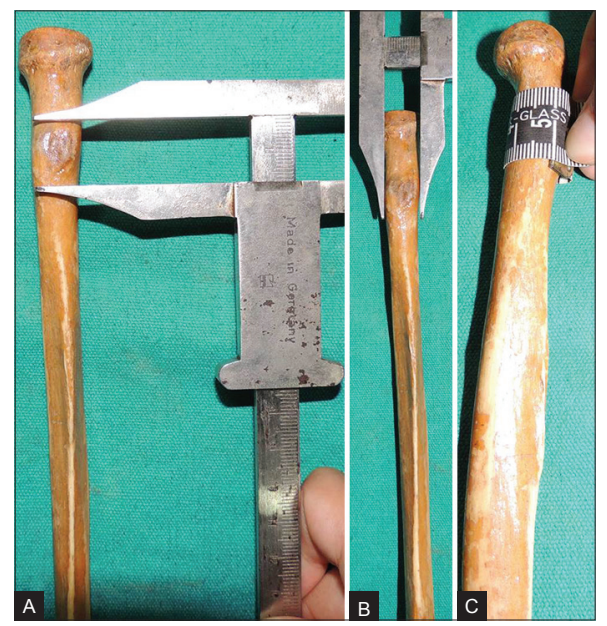

Figure 3: Various measurements done on radius: (A) length of bicipital tuberosity, (B) width of bicipital tuberosity, (C) circumference of radius at bicipital tuberosity.

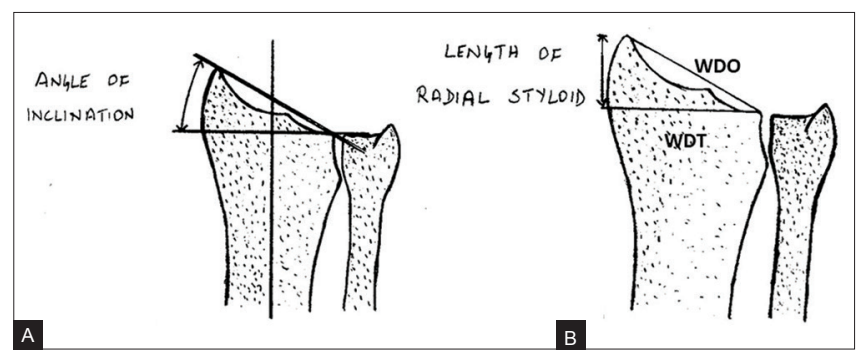

Figure 5: Various measurements done on distal end of radius: (A) angle of inclination, (B) length of styloid process (WDO- oblique width of distal end, WDT- transverse width of distal end). process, oblique and transverse width of lower end, and AP diameter of lower end in total radius were 1.19 , $1.36,1.31,1.23,1.97,4.54,0.98,2.81,2.59$, and 1.86 , respectively.

The mean angles of radial inclination in our study in total, right radius, and left radius were $25.05^{\circ}, 24.5^{\circ}$, and $25.6^{\circ}$, respectively.

Most common shape of radial head in our study was circular in 32 radii (64\%) out of total 50 radii [Figures 6 and 7]. In our study, we had two types of curvatures between neck and head of radius; they were flat and low concave and both were equal in frequency, i.e. $50 \%$.

In our study, we found single ridge on bicipital tuberosity most commonly (i.e. in $60 \%$ of cases) [Table 3].

In our study, there was no significant correlation in any parameter of radius on both right and left sides, as the $p>0.05$.

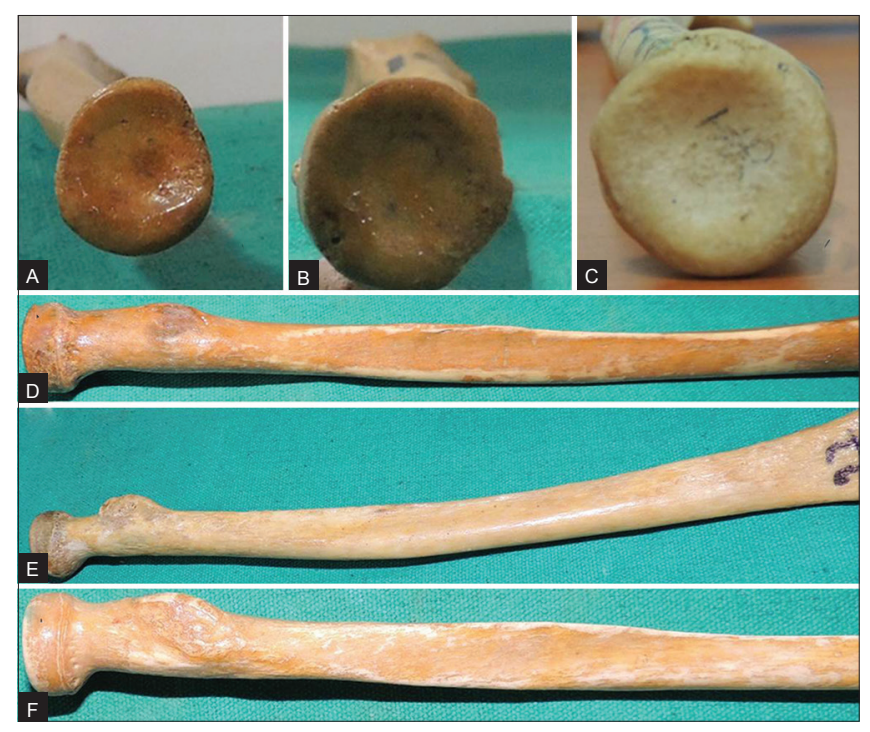

Figure 4: Morphological features of radius: (A) oval head, (B) irregular head, (C) round head, (D) smooth bicipital tuberosity, (E) single ridge on bicipital tuberosity, (F) bifid ridge on bicipital tuberosity.

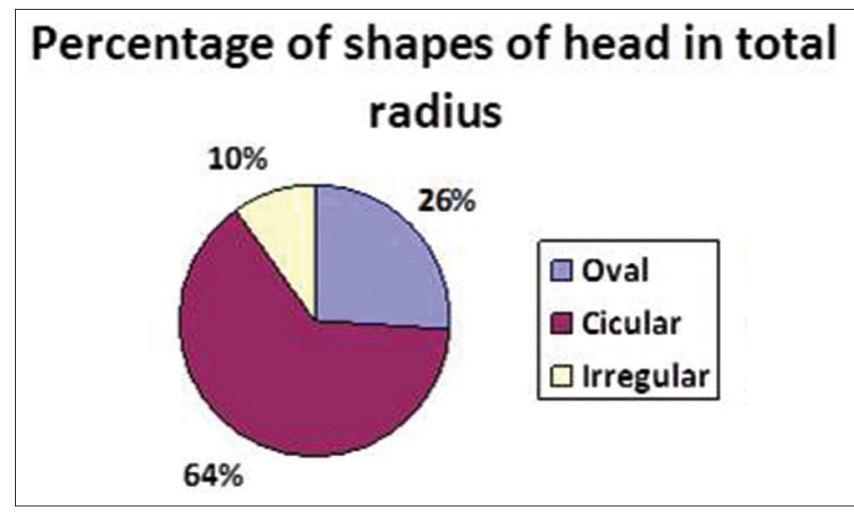

Figure 6: Various shapes of radial head in right, left, and total radius. 


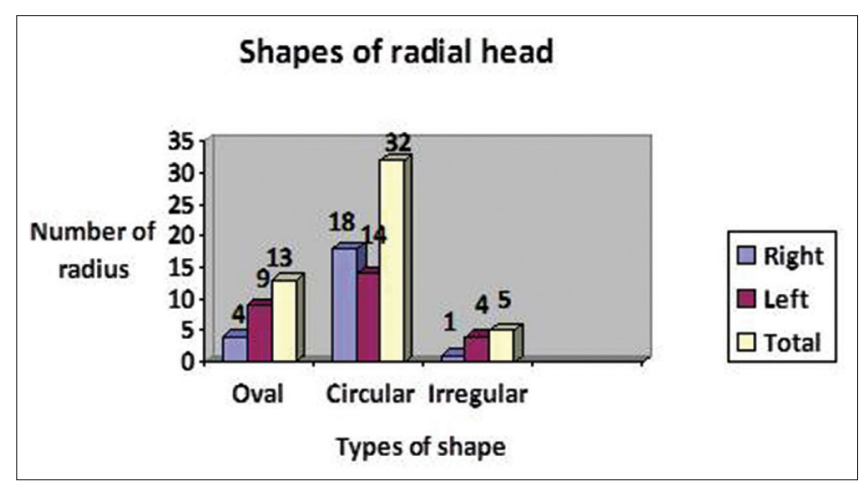

Figure 7: Percentage of various types of shapes of radial head in total radius.

Table 1: Mean and range of all parameters of radius on the right and left sides

\begin{tabular}{|c|c|c|}
\hline Parameters & Mean \pm SD $(\mathrm{cm})$ & Range $(\mathrm{cm})$ \\
\hline \multicolumn{3}{|c|}{ Length of radius } \\
\hline Right & $23.98 \pm 1.6$ & $21-27$ \\
\hline Left & $23.12 \pm 2.11$ & $20-27.40$ \\
\hline \multicolumn{3}{|c|}{ Height of radial head at medial end } \\
\hline Right & $0.91 \pm 0.10$ & $0.70-1.10$ \\
\hline Left & $0.90 \pm 0.13$ & $0.70-1.10$ \\
\hline \multicolumn{3}{|c|}{ Height of radial head at lateral end } \\
\hline Right & $0.73 \pm 0.09$ & $0.60-0.90$ \\
\hline Left & $0.77 \pm 0.14$ & $0.40-1$ \\
\hline \multicolumn{3}{|c|}{ Head AP diameter } \\
\hline Right & $1.96 \pm 0.18$ & $1.50-2.30$ \\
\hline Left & $1.87 \pm 0.21$ & $1.50-2.40$ \\
\hline \multicolumn{3}{|c|}{ Head transverse diameter } \\
\hline Right & $1.89 \pm 0.21$ & $1.50-2.30$ \\
\hline Left & $1.82 \pm 0.21$ & $1.40-2.20$ \\
\hline \multicolumn{3}{|c|}{ Head thickness ventral } \\
\hline Right & $0.43 \pm 0.05$ & $0.30-0.50$ \\
\hline Left & $0.41 \pm 0.081$ & $0.30-0.70$ \\
\hline \multicolumn{3}{|c|}{ Head thickness dorsal } \\
\hline Right & $0.32 \pm 0.06$ & $0.20-0.50$ \\
\hline Left & $0.32 \pm 0.075$ & $0.20-0.50$ \\
\hline \multicolumn{3}{|c|}{ Head thickness lateral } \\
\hline Right & $0.33 \pm 0.10$ & $0.20-0.50$ \\
\hline Left & $0.28 \pm 0.094$ & $0.10-0.40$ \\
\hline \multicolumn{3}{|c|}{ Depth of articular facet } \\
\hline Right & $0.2 \pm 0.06$ & $0.10-0.30$ \\
\hline Left & $0.19 \pm 0.051$ & $0.10-0.30$ \\
\hline \multicolumn{3}{|l|}{ Neck length } \\
\hline Right & $1.18 \pm 0.25$ & $0.70-1.90$ \\
\hline Left & $1.20 \pm 0.31$ & $0.70-2.10$ \\
\hline \multicolumn{3}{|c|}{ Proximal neck diameter } \\
\hline Right & $1.36 \pm 0.22$ & $1-1.80$ \\
\hline Left & $1.35 \pm 0.16$ & $1.10-1.70$ \\
\hline \multicolumn{3}{|c|}{ Distal neck diameter } \\
\hline Right & $1.33 \pm 0.19$ & $1-1.70$ \\
\hline Left & $1.29 \pm 0.19$ & $1-1.80$ \\
\hline
\end{tabular}

\section{DISCUSSION}

Operative treatment of displaced and comminuted radial head fractures requires internal fixation with plates and screws in cases where reconstruction can be done and replacement with a radial head prosthesis when the radial head is unreconstructable. ${ }^{[7]}$ Some biomechanical studies have emphasized the importance of correctly sizing the radial head prosthesis at the time of implantation ${ }^{[8]}$ In unstable elbow fractures, accurate implant size is a significant factor to prevent subluxation of the radial head. ${ }^{[7]}$

Puchwein et al. ${ }^{[7]}$ and Captier et al. ${ }^{[9]}$ found the mean AP diameter of the radial head at its widest part as 2.3 and $2.16 \mathrm{~cm}$, respectively, and in the transverse plane as 2.24 and $2.1 \mathrm{~cm}$, respectively, while in our study, we got the values as 1.91 and $1.85 \mathrm{~cm}$, respectively. Puchwein et al. also found the mean radial head length on medial and lateral sides as 1.17 and $1.18 \mathrm{~cm}$, respectively, while in our study we got the values as 0.9 and $0.75 \mathrm{~cm}$, respectively. ${ }^{[7]}$ Our values are less than those reported by Puchwein et al., which may be because they measured the values on CT scan and we did it on dry bone.

Captier et al. also found that the radial head was elliptical in $57 \%$ of cases and circular in $43 \%$ of cases, but in our study we got the most common shape as circular in $64 \%$ of cases, oval in $26 \%$, and irregular in $10 \%$ of cases. They also found that biomechanics of the circular shape and elliptical shape are different, involving an adaptation of the angle between the neck and the radial diaphysis. This modification must be taken into concern in the design of radial head prosthesis. ${ }^{[9]}$

Van Riet et al. found the mean radial length as $23.5 \mathrm{~cm}$ and the mean radial neck length as $1.3 \mathrm{~cm}$, and we also got similar values in our study $\left(23.5\right.$ and $1.19 \mathrm{~cm}$, respectively). ${ }^{[10]}$

Swieszkowski et al. found the mean depth of articular facet as $0.19 \mathrm{~cm}$, and we also got similar value in our study $(0.19 \mathrm{~cm}) .^{[11]}$

Mazzocca et al. found the mean length and width of bicipital tuberosity as 2.2 and $1.5 \mathrm{~cm}$, respectively. They also found that the bicipital tuberosity ridge was smooth in $6 \%$ of specimens, bifid in $6 \%$, and the remaining $88 \%$ of specimens had a single ridge. ${ }^{[12]}$ In our study, we found the mean length and width of bicipital tuberosity as 1.97 and $1.23 \mathrm{~cm}$, respectively. Our values were slightly less than theirs. In our study also, we found mainly single ridge on bicipital tuberosity (in $60 \%$ of cases); we also found smooth bicipital tuberosity in $36 \%$ of cases and bifid in $4 \%$ of cases.

Prithishkumar et al. found the mean radial inclination as $21.8^{\circ}$ on the left side and $22.1^{\circ}$ on the right side. They found the mean length of radius, length of radial styloid 
Table 2: Mean and range of all parameters of radius on the right and left sides

\begin{tabular}{|c|c|c|}
\hline Parameters & Mean \pm SD & Range \\
\hline \multicolumn{3}{|c|}{ Width of bicipital tuberosity } \\
\hline Right & $1.25 \pm 0.15$ & $1-1.60$ \\
\hline Left & $1.21 \pm 0.19$ & $1-1.70$ \\
\hline \multicolumn{3}{|c|}{ Length of bicipital tuberosity } \\
\hline Right & $2.02 \pm 0.29$ & $1.20-2.60$ \\
\hline Left & $1.92 \pm 0.35$ & $0.80-2.80$ \\
\hline \multicolumn{3}{|c|}{ Radial circumference } \\
\hline Right & $4.65 \pm 0.45$ & $3.70-5.60$ \\
\hline Left & $4.45 \pm 0.48$ & $3.70-5.40$ \\
\hline \multicolumn{3}{|c|}{ Length of styloid process } \\
\hline Right & $1 \pm 0.13$ & $0.80-1.20$ \\
\hline Left & $0.97 \pm 0.14$ & $0.70-1.20$ \\
\hline \multicolumn{3}{|c|}{ Oblique width of lower end } \\
\hline Right & $2.83 \pm 0.21$ & $2.40-3.30$ \\
\hline Left & $2.78 \pm 0.23$ & $2.40-3.20$ \\
\hline \multicolumn{3}{|c|}{$\begin{array}{l}\text { Transverse width of lower } \\
\text { end }\end{array}$} \\
\hline Right & $2.64 \pm 0.22$ & $2.10-3.10$ \\
\hline Left & $2.55 \pm 0.27$ & $2-3.10$ \\
\hline \multicolumn{3}{|c|}{ AP diameter of lower end } \\
\hline Right & $1.89 \pm 0.21$ & $1.60-2.30$ \\
\hline Left & $1.84 \pm 0.22$ & $1.50-2.40$ \\
\hline
\end{tabular}

Table 3: Different types of morphological variants of bicipital tuberosity

\begin{tabular}{lccc}
\hline $\begin{array}{l}\text { Morphological variants } \\
\text { of bicipital tuberosity }\end{array}$ & Single ridge & Smooth & Double ridge \\
\hline Right & 14 & 7 & 2 \\
Left & 16 & 11 & 0 \\
Total & $30(60 \%)$ & $18(36 \%)$ & $2(4 \%)$ \\
\hline
\end{tabular}

process, transverse and oblique width of distal end, and the AP diameter of distal end as 24.4, 1.1, 2.67, 2.72, and $1.78 \mathrm{~cm}$, respectively, on the left side and 24.2, 1.08, 2.63, 2.67 , and $1.75 \mathrm{~cm}$, respectively, on the right side. ${ }^{[13]}$ In our study, we found the angle of radial inclination as $25.6^{\circ}$ on the left side and $24.5^{\circ}$ on the right side. Our values were slightly higher than theirs. We found the mean length of radius, length of radial styloid process, transverse and oblique width of distal end, and the AP diameter of distal end as $23.12,0.97,2.55,2.78$, and $1.84 \mathrm{~cm}$, respectively, on the left side and 23.9, 1.0, 2.64, 2.83, and $1.89 \mathrm{~cm}$, respectively, on the right side. Our values were almost similar to their values.

Chan et al., Gartland and Werley, Schuind et al., and Werner et al. found the mean value of radial inclination as $25.1^{\circ}, 23^{\circ}, 24^{\circ}$, and $30^{\circ}$, respectively. ${ }^{[14-17]}$ In our study, we got the angle of radial inclination as $25.05^{\circ}$, which was almost similar to the values obtained by Chan et al., Gartland and Werley, and Schuind et al.

These dimensions of the bicipital tuberosity, radial head, and radial styloid process will facilitate in various surgical procedures such as reconstruction of the distal biceps tendon, radial head prosthesis implantation, and reconstruction of proximal radius trauma. ${ }^{[12]}$

New modular designs have enhanced sizing to better replicate the anatomy of the proximal radius, and they are easier to insert intraoperatively. ${ }^{[18]}$ Smith et al. found that the "safe zone" is approximately one-third of the radial head circumference and can be reliably determined with the technique of intraoperative marking as delineated. ${ }^{[19]}$

Giannicola et al. found that the outline of the proximal radius in the safe zone displays extensive morphologic dissimilarities that should be taken into account when operating on fractures of the proximal radius, to prevent malunions, pain, and stiffness of the elbow joint. They are also of the opinion that osteosynthesis of radial head and neck fractures should be done in safe zone, where a plate can be securely applied without risking the proximal radioulnar joint. ${ }^{[20]}$

In our study, we also looked for prevalence of types of curvature at the head and neck zone and we classified the curvature as flat or low concave. Also, in our study, both flat and low concave were equal in frequency, i.e. $50 \%$. Knowledge of the proper bending radius of the safe zone allows the surgeon to select the most appropriate plate and to achieve good fracture reduction and anatomical restoration of the proximal radius. ${ }^{[20]}$

\section{REFERENCES}

1. Caputo AE, Mazzocca AD, Santoro VM. The nonarticulating portion of the radial head: Anatomic and clinical correlations for internal fixation. J Hand Surg Am 1998;23:1082-90.

2. Jupier JB, Masem M. Reconstruction of post-traumatic deformity of the distal radius and ulna. Hand Clin 1988;4:377-90.

3. van Earten PV, Lindeboom R, Oosterkamp AE, Goslings JC. An $\mathrm{X}$-ray template assessment for distal radial fractures. Arch Orthop Trauma Surg 2008;128:217-21.

4. Hove LM, Fjeldsgaard K, Skjeie R, Solheim E. Anatomical and functional results five years after remanipulated Colles' fractures. Scand J Plast Reconstr Surg Hand Surg 1995;29:349-55.

5. Leung F, Ozkan M, Chow SP. Conservative treatment of intra-articular fractures of the distal radius and factors affecting functional outcome. Hand Surg 2000;5:145-53.

6. Slutsky DJ. Predicting the outcome of distal radius fractures. Hand Clin 2005;21:289-94.

7. Puchwein P, Heidari N, Dorr K, Struger L, Pichler W. Computer-aided analysis of radial head morphometry. Orthopedics 2013;36:e51-7.

8. Tejwani NC, Mehta H. Fractures of the radial head and neck: current concepts in management. J Am Acad Orthop Surg 2007;15:380-7.

9. Captier G, Canovas F, Mercier N, Thomas E, Bonnel F. Biometry of the radial head: Biomechanical implications in pronation and supination. Surg Radiol Anat 2002;24:295-301.

10. Van Riet RP, Van Glabbeek F, Neale PG, Bimmel R, Bortier H, 
Morrey BF, et al. Anatomical considerations of the radius. Clin Anat 2004; 17:564-9.

11. Swieszkowski W, Skalski K, Pomianowski S, Kedzior K. The anatomic features of the radial head and their implication for prosthesis design. Clin Biomech (Bristol, Avon) 2001;16:880-7.

12. Mazzocca AD, Cohen M, Berkson E, Nicholson G, Carofino BC, Arciero R, et al. The anatomy of the bicipital tuberosity and distal biceps tendon. J Shoulder Elbow Surg 2007;16:122-7.

13. Prithishkumar IJ, Francis DV, Nithyanand M, Verghese VD, Samuel P. Morphometry of the distal radius - an osteometric study in the Indian population. Indian J Basic Appl Med Res 2012;1:166-71.

14. Chan CY, Vivek AS, Leong WH, Rukmanikanthan S. Distal radius morphometry in the Malaysian Population. Malays Orthop J 2008;2:27-30.

15. Gartland JJ Jr, Werley CW. Evaluation of healed colles fractures. J Bone Joint Surg Am 1951;33:895-907.
16. Schuind FA, Linscheid RL, An K, Chao EY. A normal data base of posteroanterior roentgenographic measurements of the wrist. J Bone Joint Surg Am 1992;74:1418-29.

17. Werner FW, Palmer AK, Fortino MD, Short WH. Force transmission through the distal ulna: Effect of ulnar variance, lunate fossa angulation, and radial and palmar tilt of the distal radius. J Hand Surg 1992;17:423-8.

18. Chien HY, Chen AC, Huang JW, Cheng CY, Hsu KY. Short- to medium-term outcomes of radial head replacement arthroplasty in posttraumatic unstable elbows: 20 to 70 months follow-up. Chang Gung Med J 2010;33:668-78.

19. Smith GR, Hotchkiss RN. Radial head and neck fractures: Anatomic guidelines for proper placement of internal fixation. J Shoulder Elbow Surg 1996;5:113-7.

20. Giannicola G, Manauzzi E, Sacchetti FM, Greco A, Bullitta G, Vestri A, et al. Anatomical variations of the proximal radius and their effects on osteosynthesis. J Hand Surg Am 2012;37:1015-23. 